\title{
Effects of intradiscal vacuum phenomenon on surgical outcome of lateral interbody fusion for degenerative lumbar disease
}

\author{
Chun-Po Yen, MD, ${ }^{1,2}$ Joshua M. Beckman, MD, ${ }^{1}$ Andrew C. Vivas, MD, ${ }^{1}$ Konrad Bach, MD, ${ }^{1}$ and \\ Juan S. Uribe, MD1 \\ 1Department of Neurological Surgery, University of South Florida, Tampa, Florida; and 'Department of Neurological Surgery, \\ University of Virginia Heath System, Charlottesville, Virginia
}

\begin{abstract}
OBJECTIVE The authors investigated whether the presence of intradiscal vacuum phenomenon (IVP) results in greater correction of disc height and restoration of segmental lordosis (SL).

METHODS A retrospective chart review was performed on every patient at the University of South Florida's Department of Neurosurgery treated with lateral lumbar interbody fusion between 2011 and 2015. From these charts, preoperative plain radiographs and CT images were reviewed for the presence of IVP. Preoperative and postoperative posterior disc height (PDH), anterior disc height (ADH), and SL were measured at disc levels with IVP and compared with those at disc levels without IVP using the t-test. Linear regression was used to evaluate the factors that predict changes in PDH, ADH, and SL.
\end{abstract}

RESULTS One hundred forty patients with 247 disc levels between L-1 and L-5 were treated with lateral lumbar interbody fusion. Among all disc levels treated, the mean PDH increased from 3.69 to $6.66 \mathrm{~mm}(p=0.011)$, the mean ADH increased from 5.45 to $11.53 \mathrm{~mm}(p<0.001)$, and the mean SL increased from $9.59^{\circ}$ to $14.55^{\circ}(p<0.001)$. Significantly increased PDH was associated with the presence of IVP, addition of pedicle screws, and lack of cage subsidence; significantly increased ADH was associated with the presence of IVP, anterior longitudinal ligament (ALL) release, addition of pedicle screws, and lack of subsidence; and significantly increased SL was associated with the presence of IVP and ALL release.

CONCLUSIONS IVP in patients with degenerative spinal disease remains grossly underreported. The data from the present study suggest that the presence of IVP results in increased restoration of disc height and SL.

https://thejns.org/doi/abs/10.3171/2016.8.SPINE16421

KEY WORDS adult spinal deformity; degenerative disc disease; lateral lumbar interbody fusion; scoliosis; spondylolisthesis; vacuum phenomenon

I NTRADISCAL vacuum phenomenon (IVP) refers to the radiographic appearance of gas within an intervertebral disc space. Its prevalence on conventional radiographs ranges from $2 \%$ in healthy adults to $21 \%$ in asymptomatic elderly people. ${ }^{22}$ Although IVP can occur with spinal infection or neoplasm, ${ }^{3,5,13}$ it is associated more commonly with advanced stages of degenerative spinal disease..$^{13,19}$ Among patients with this condition, IVP can be seen in $52 \%-73 \%$ of them. ${ }^{6,27}$ Evidence has shown that IVP is associated with spinal instability. ${ }^{18,19,27}$

In patients with IVP, the relative mobility of the disc space might allow greater correction of sagittal and coronal deformities. If true, the presence of IVP might affect surgical planning and obviate the need for more advanced corrective maneuvers such as anterior column release or posterior osteotomy. The purpose of this study was to compare the degree of deformity correction in patients who underwent lateral lumbar interbody fusion (LLIF) with or without percutaneous posterior instrumentation and had associated IVP with that of such patients without IVP, as measured by disc-height restoration and improved segmental lordosis (SL).

ABBREVIATIONS ADH = anterior disc height; $\mathrm{ALL}$ = anterior longitudinal ligament; IVP = intradiscal vacuum phenomenon; LLIF = lateral lumbar interbody fusion; MIS = minimally invasive surgical; $\mathrm{PDH}=$ posterior disc height; $\mathrm{SL}=$ segmental lordosis.

SUBMITTED April 14, 2016. ACCEPTED August 31, 2016.

INCLUDE WHEN CITING Published online December 16, 2016; DOI: 10.3171/2016.8.SPINE16421. 


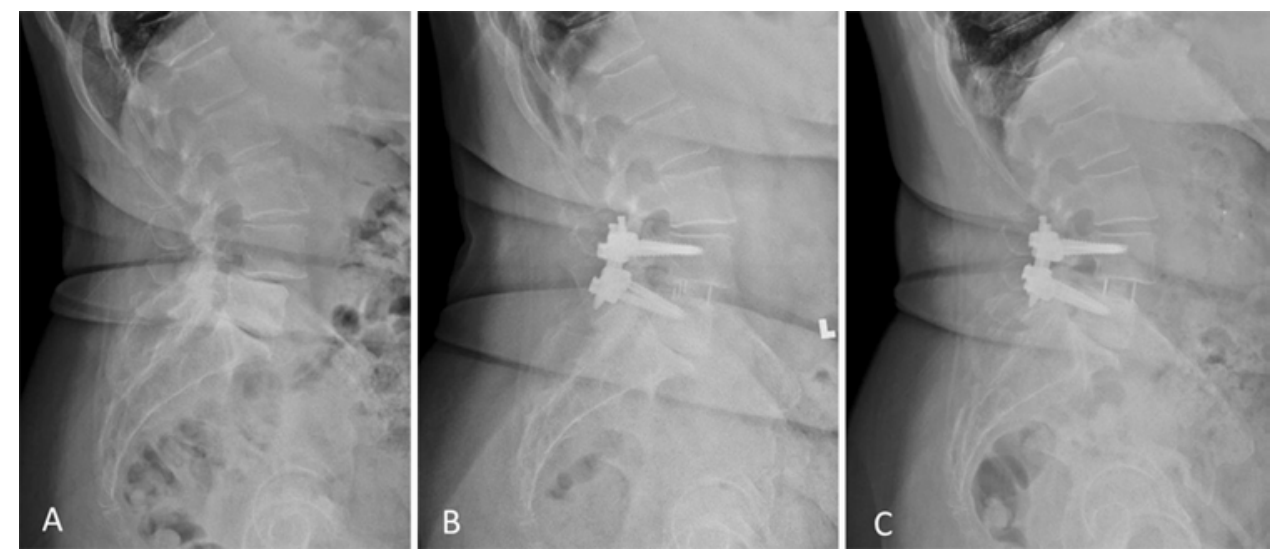

FIG. 1. A 70-year-old woman presented with back pain and leg pain (right greater than left). MRI (not shown) revealed moderate spinal canal and foraminal stenosis at the L4-5 level. A: Preoperative upright lateral radiograph revealing L4-5 degenerative Grade I spondylolisthesis. Also noted is IVP at the L4-5 and L5-S1 disc spaces. B: Postoperative Day 1 upright lateral radiograph, after L4-5 LLIF and placement of percutaneous pedicle screws and rods, showing the interbody cage and reduction of the listhesis. C: Lateral upright radiograph obtained 24 months after surgery revealing fusion at the L4-5 level without evidence of cage subsidence.

\section{Methods \\ Patient Population}

Review of a prospectively maintained database was performed to identify all patients treated with minimally invasive surgical (MIS) LLIF with or without placement of posterior percutaneous pedicle screws/rods for degenerative spinal pathology (including degenerative disc disease, degenerative spondylolisthesis, and adult degenerative deformity with coronal and/or sagittal imbalance) between October 2011 and July 2015 at the University of South Florida's Department of Neurosurgery. Patients who underwent a hybrid procedure (posterior osteotomy, instrumentation, and fusion procedure other than placement of percutaneous pedicle screws) were excluded. Preoperative plain radiographs and CT, MR, and intraoperative fluoroscopic images were reviewed for the presence of IVP. Patient demographics, including age, sex, and details of surgical procedures, were retrieved from the medical record.

\section{Surgical Technique}

The details of MIS LLIF were given previously. ${ }^{28}$ In brief, patients were placed in a true lateral position. A lateral incision was made, and dissection was performed down to the abdominal wall musculature. Dilation of the abdominal musculature was then performed to create a corridor to the retroperitoneal space. The psoas muscle was then dilated under the guidance of fluoroscopy and triggered electromyography. Once a satisfactory trajectory to the disc space was created, an expandable tubular retractor was inserted. A discectomy was performed, and the cartilaginous endplates were removed. Trials were placed into the disc space for a snug fit. Ten-degree lordotic, 18- to 22-mm-wide, 8- to 12-mm-high, 50- to 60-mm-long polyetheretherketone (PEEK) cages filled with $5 \mathrm{ml}$ of cadaveric cancellous bone mixed with mesenchymal stem cells (Osteocel, NuVasive) were placed according to the trials in an attempt to restore lumbar lordosis. In patients with significant sagittal imbalance, anterior longitudinal ligament (ALL) release was performed, followed by placement of a hyperlordotic cage $\left(20^{\circ}\right.$ or $\left.30^{\circ}\right)$ to correct pelvic incidence-lumbar lordosis mismatch. ${ }^{8}$ Placement of supplementary percutaneous pedicle screws and rod fixation were performed in patients with evidence of overt spinal instability or spondylolisthesis and in those who were undergoing long-segment LLIF. ${ }^{2}$

\section{Postoperative Follow-Up}

Patients returned to the clinic 1,3,6, and 12 months and then yearly after surgery for upright radiographs. The most recent postoperative radiographs were used for comparison with preoperative radiographs. Preoperative and postoperative posterior disc height (PDH), anterior disc height $(\mathrm{ADH})$, and SL at the operative levels were measured digitally on standing radiographs using Centricity 3.0 workstations (GE Healthcare). The measurements were performed by 2 independent observers (C.P.Y. and K.B.), and averages were used for analysis. We arbitrarily determined that measurement disagreements greater than $15 \%$ between the 2 observers would be reviewed further by the senior author (J.S.U.). PDH and ADH were the distances between the superior and inferior endplates of the disc space at the posterior and anterior borders of the vertebrae, respectively. SL was defined as the angle between the cranial and caudal endplates of the upper and lower vertebrae of the segment subjected to surgery (Fig. 1). Deformity correction, cage subsidence, and construct integrity were assessed also. The degree of cage subsidence was classified based on loss of immediate postoperative disc height (Grade 0, 0\%-24\% loss; Grade I, 25\%-49\% loss; Grade II, 50\%-74\% loss; and Grade III, 75\%-100\% loss), as described by Marchi et al. ${ }^{16}$ Fusion was defined as the existence of bridging bone between the treated intervertebral endplates and lack of intervertebral movement on flexion/extension lateral radiographs.

\section{Statistics}

Statistical analyses were performed using the statistical software package SPSS 25.0 (SPSS IBM). Comparisons 
of nominal measurements were made using the chi-square test. Continuous data were compared using the t-test. We used univariate linear regression to evaluate factors that predict changes in $\mathrm{PDH}, \mathrm{ADH}$, and SL, and then we used a multivariate analysis in which only those factors that were significant in the univariate analysis were entered. Factors evaluated include patient age and sex, procedure performed (LLIF only, ALL release, placement of percutaneous pedicle screws), level of surgery, presence of spondylolisthesis, cage subsidence, and IVP. The same factors were evaluated for their relationship with subsidence by using logistic regression. A p value of less than 0.05 was used as the limit for statistic significance.

\section{Results \\ Patient Population}

A total of 140 patients underwent MIS LLIF with or without placement of posterior percutaneous pedicle screws/rods. There were $61(43.6 \%)$ males and $79(56.4 \%)$ females; the mean age was 62 years (range $30-88$ years). Seventy-six patients underwent 1-level, 29 underwent 2-level, 27 underwent 3-level, and 8 underwent 4-level LLIF(s). Ninety-two (65.7\%) patients with at least 1 disc level with IVP underwent surgery (1 level in 53, 2 levels in 21, 3 levels in 13, and 4 levels in 5 patients); 48 (34.3\%) patients had no IVP at any surgical level. Fifteen patients underwent at least 1-level ALL release (11 underwent 1-level and 4 underwent 2-level ALL release). Fifty-two (37.1\%) patients underwent stand-alone LLIF, and 88 (62.9\%) underwent placement of supplementary posterior percutaneous pedicle screws/rods. Seven-five patients had at least 1 level with spondylolisthesis. The follow-up duration ranged from 6 to 42 months (mean 12 months).

\section{Disc Levels}

A total of 247 lumbar disc levels were surgically treated, including 15 at L1-2, 47 at L2-3, 83 at L3-4, and 102 at L4-5. ALL release was performed at 19 levels (3 at L23, 10 at L3-4, and 6 at L4-5). Percutaneous screw fixation was performed at 168 levels. IVP was observed at a total of 155 surgical levels and not observed at 92 levels. Spondylolisthesis was observed at 100 levels.

\section{Radiographic Outcomes}

Among all disc levels treated, the mean PDH increased from 3.69 to $6.66 \mathrm{~mm}(\mathrm{p}=0.011)$, the mean $\mathrm{ADH}$ increased from 5.45 to $11.53 \mathrm{~mm}(\mathrm{p}<0.001)$, and the mean SL increased from $9.59^{\circ}$ to $14.55^{\circ}$ ( $\left.\mathrm{p}<0.001\right)$. ALL release was performed at 19 disc levels; among these levels, the mean PDH increased from 3.52 to $7.04 \mathrm{~mm}(\mathrm{p}=$ 0.016), the mean ADH from 4.57 to $15.90 \mathrm{~mm}$ ( $\mathrm{p}<0.001)$, and the mean SL from $2.80^{\circ}$ to $15.48^{\circ}(\mathrm{p}=0.001)$. For the 228 levels with LLIF only, the mean PDH increased from 3.70 to $6.62 \mathrm{~mm}$, the mean $\mathrm{ADH}$ from 5.53 to $11.17 \mathrm{~mm}$, and the mean SL from $10.15^{\circ}$ to $14.47^{\circ}$ ( $\mathrm{p}<0.001$ for all) (Table 1).

Among all the levels treated, significantly increased $\mathrm{PDH}$ was associated with the presence of IVP, addition of pedicle screws, and lack of cage subsidence in univariate and multivariate regression analyses. Significantly in-
TABLE 1. Preoperative and postoperative PDHs, ADHs, and SL

\begin{tabular}{cccc}
\hline Parameter & Preop & Postop & Change \\
\hline All disc levels $(n=247)$ & & & \\
\hline PDH $(\mathrm{mm})$ & $3.69 \pm 1.97$ & $6.66 \pm 2.35$ & $3.00 \pm 2.95$ \\
\hline $\mathrm{ADH}(\mathrm{mm})$ & $5.45 \pm 2.72$ & $11.53 \pm 3.77$ & $6.13 \pm 4.89$ \\
\hline $\mathrm{SL}\left({ }^{\circ}\right)$ & $9.59 \pm 9.35$ & $14.55 \pm 9.20$ & $5.12 \pm 8.08$ \\
\hline $\mathrm{LLIF}$ only $(\mathrm{n}=228)$ & & & \\
\hline $\mathrm{PDH}(\mathrm{mm})$ & $3.70 \pm 1.88$ & $6.62 \pm 2.29$ & $2.96 \pm 2.77$ \\
\hline $\mathrm{ADH}(\mathrm{mm})$ & $5.53 \pm 2.73$ & $11.17 \pm 3.49$ & $5.70 \pm 4.14$ \\
\hline $\mathrm{SL}\left({ }^{\circ}\right)$ & $10.15 \pm 9.43$ & $14.47 \pm 9.40$ & $4.42 \pm 7.62$ \\
\hline $\mathrm{ALL}$ release $(\mathrm{n}=19)$ & & & \\
\hline $\mathrm{PDH}(\mathrm{mm})$ & $3.52 \pm 2.84$ & $7.04 \pm 2.95$ & $3.53 \pm 3.86$ \\
\hline $\mathrm{ADH}(\mathrm{mm})$ & $4.57 \pm 2.63$ & $15.90 \pm 4.36$ & $11.33 \pm 5.34$ \\
\hline $\mathrm{SL}\left({ }^{\circ}\right)$ & $2.80 \pm 4.60$ & $15.48 \pm 6.51$ & $13.50 \pm 8.88$ \\
\hline
\end{tabular}

Values are means $\pm S D$. All parameters improved significantly after surgery $(p$ $<0.001$, t-test)

creased $\mathrm{ADH}$ was associated with the presence of IVP, ALL release, addition of pedicle screws, and lack of subsidence in univariate and multivariate regression analyses. Significantly increased SL was associated with the presence of IVP, ALL release, and lack of subsidence in univariate analysis but with only the presence of IVP and ALL release in multivariate analysis (Table 2). Among the levels treated with LLIF without ALL release, the presence of IVP significantly increased postoperative PDH, $\mathrm{ADH}$, and SL; the addition of pedicle screws and lack of subsidence significantly increased postoperative PDHs and ADHs but not SL (Table 3). In the ALL-release group, there were no associations between any of the studied patient factors and changes in PDH, ADH, or SL (Table 4). In the LLIF-only group, the mean increase in SL was $2^{\circ}$ at the levels at which IVP was absent compared with $5.9^{\circ}$ for the levels at which IVP was present $(\mathrm{p}<0.001)$. In the ALL-release group, the mean increase of SL at levels at which IVP was absent was $10.3^{\circ}$ compared with $15.0^{\circ}$ for the levels at which IVP was present $(\mathrm{p}=0.301)$ (Table 5).

Subsidence at the end of follow-up was observed in 52 (21.1\%) levels; there was Grade I subsidence at 45 levels and Grade II subsidence at 7 levels. None of the studied patient factors (including age, sex, ALL release, presence of IVP, and length of follow-up) except the addition of pedicle screws $(\mathrm{p}=0.009)$ affected the incidence of subsidence. Twenty-two (27.8\%) of 79 levels without pedicle screws developed subsidence; 30 (17.9\%) of 168 levels with pedicle screws developed subsidence. Fusion was observed in $92 \%$ of the levels treated.

\section{Discussion}

\section{Pathogenesis of IVP}

The pathogenesis of IVP is debatable and most likely multifactorial. The prevailing hypothesis for gas formation in a degenerative disc is based on the endplate-degeneration theory. As vertebral endplates degenerate, the hyaline cartilage becomes calcified, and inflammatory cytokines are produced. This combination blocks the nutritional pathways, which results in metabolic imbalance and 

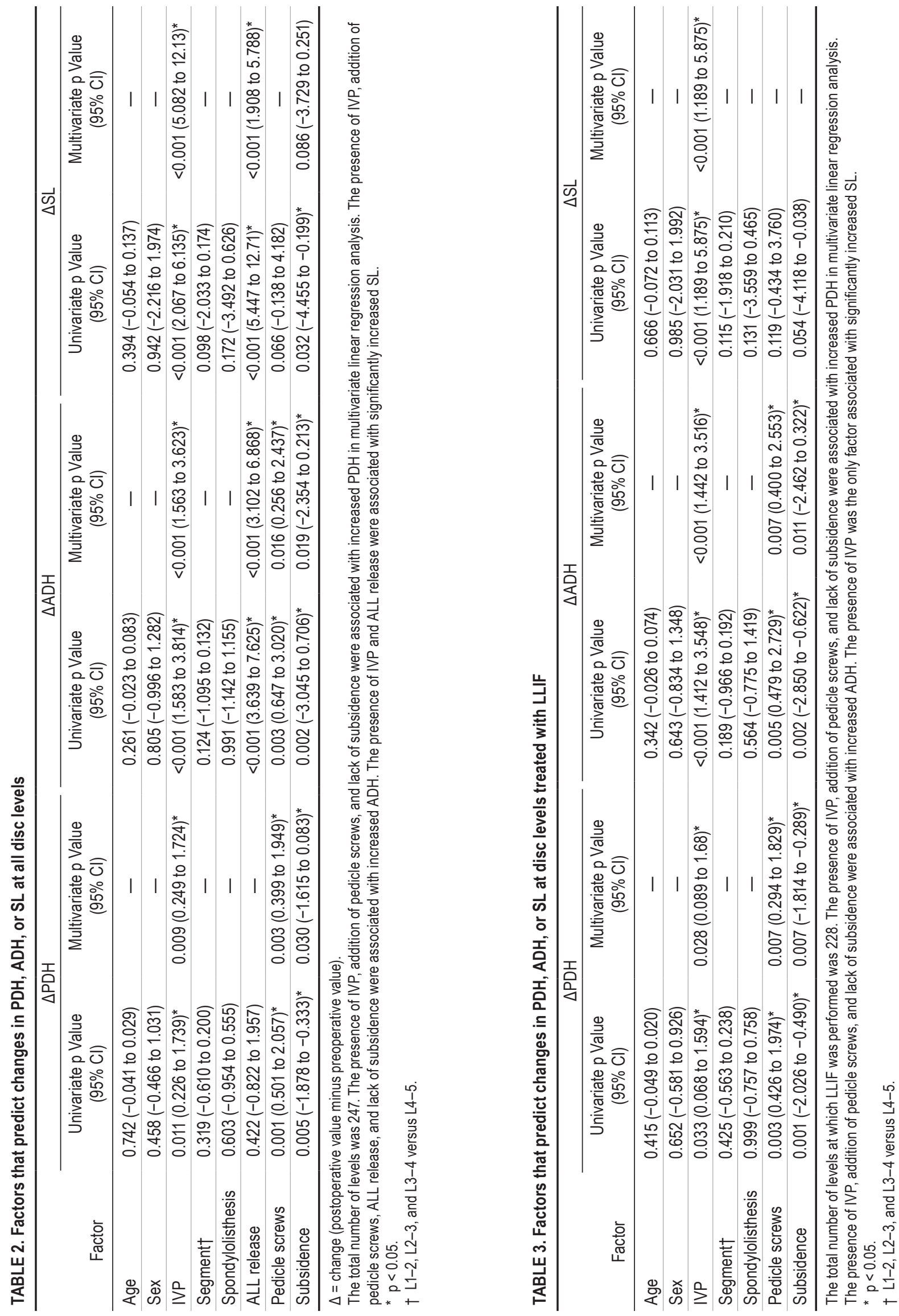
TABLE 4. Factors that predict changes in PDH, ADH, or SL at disc levels treated with ALL release

\begin{tabular}{lccc}
\hline \multicolumn{1}{c}{ Factor } & $\begin{array}{c}\Delta \mathrm{PDH} \\
\text { (univariate } \mathrm{p} \text { value }[95 \% \mathrm{Cl}])\end{array}$ & $\begin{array}{c}\Delta \mathrm{ADH} \\
\text { (univariate } \mathrm{p} \text { value }[95 \% \mathrm{Cl}])\end{array}$ & $\begin{array}{c}\Delta \mathrm{SL} \\
\text { (univariate } \mathrm{p} \text { value }[95 \% \mathrm{Cl}])\end{array}$ \\
\hline Age & $0.392(-0.099$ to 0.241$)$ & $0.304(-0.148$ to 0.446$)$ & $0.277(-0.236$ to 0.773$)$ \\
\hline Sex & $0.873(-2.808$ to 3.227$)$ & $0.451(-7.210$ to 3.349$)$ & $0.470(-12.187$ to 5.862$)$ \\
\hline IVP & $0.163(-0.922$ to 5.036$)$ & $0.054(-0.105$ to 9.862$)$ & $0.301(-4.559$ to 13.864$)$ \\
\hline Segment $^{*}$ & $0.252(-3.291$ to 0.923$)$ & $0.205(-6.034$ to 1.391$)$ & $0.216(-10.14$ to 2.467$)$ \\
\hline Spondylolisthesis & $0.482(-4.405$ to 2.166$)$ & $0.839(-5.342$ to 6.503$)$ & $0.149(-2.678$ to 16.182$)$ \\
\hline Pedicle screws & $0.450(-2.981$ to 6.426$)$ & $0.472(11.212$ to 5.410$)$ & $0.280(-21.268$ to 6.553$)$ \\
\hline Subsidence & $0.413(-2.125$ to -4.935$)$ & $0.871(-6.899$ to -5.900$)$ & $0.940(-11.241$ to -10.451$)$ \\
\hline
\end{tabular}

The total number of levels at which ALL release was performed was 19. None of the factors analyzed predicted changes in PDH, ADH, or SL.

* $\mathrm{L} 1-2, \mathrm{~L} 2-3$, and $\mathrm{L} 3-4$ versus $\mathrm{L} 4-5$.

decreased synthesis of structural matrix proteins. As a result, the structural integrity of the disc becomes unstable, and the continuous compression-and-distraction motion creates a cleft that is filled gradually with gas. ${ }^{13}$ Intradiscal gas typically is composed of $90 \%-92 \%$ nitrogen, and the remaining fraction consists of oxygen, carbon dioxide, and other traces of gases. ${ }^{9,29}$ The literature shows that IVP is associated with spinal instability. ${ }^{18,19,27}$ Adjacent bone marrow changes have been observed on MRI when IVP is present, but the clinical significance of that finding is not clear. ${ }^{27}$

\section{Implications of IVP in Surgery}

LLIF has been used to treat degenerative disc disease with instability and adult spinal deformity. Studies have found that sagittal spinopelvic malalignment from advanced degeneration is a major cause of pain and loss of function. ${ }^{23}$ Surgeries that fail to restore normal sagittal vertical axis and spinopelvic harmony will lead to an unsatisfactory outcome, pseudarthrosis, and proximal junctional kyphosis. ${ }^{10}$ Therefore, sagittal balance should be considered carefully when deciding to perform a lumbar fusion procedure, even in patients with normal spinopelvic parameters or who are undergoing short-segment fusion, because failure to fuse the spine in a lordotic fashion can

TABLE 5. Changes in PDH, ADH, and SL after LLIF or ALL release at disc levels with or without IVP

\begin{tabular}{|c|c|c|c|c|}
\hline \multirow{2}{*}{$\begin{array}{c}\text { Parameter } \\
\text { Changes }\end{array}$} & \multirow{2}{*}{$\begin{array}{c}\text { All } \\
\text { Levels }\end{array}$} & \multicolumn{2}{|c|}{ IVP } & \multirow{2}{*}{$\begin{array}{c}p \\
\text { Value }\end{array}$} \\
\hline & & Absent & Present & \\
\hline \multicolumn{5}{|l|}{$\Delta \mathrm{PDH}(\mathrm{mm})$} \\
\hline LLIF only $(n=228)$ & 2.9 & 2.5 & 3.2 & 0.043 \\
\hline ALL release $(n=19)$ & 3.5 & 0.9 & 4.8 & 0.065 \\
\hline \multicolumn{5}{|l|}{$\triangle \mathrm{ADH}(\mathrm{mm})$} \\
\hline LLIF only $(n=228)$ & 5.7 & 4.2 & 6.6 & $<0.001$ \\
\hline ALL release $(n=19)$ & 11.3 & 8.5 & 12.6 & 0.012 \\
\hline \multicolumn{5}{|l|}{$\Delta S L\left({ }^{\circ}\right)$} \\
\hline LLIF only $(n=228)$ & 4.4 & 2.0 & 5.9 & $<0.001$ \\
\hline ALL release $(n=19)$ & 13.5 & 10.3 & 15.0 & 0.301 \\
\hline
\end{tabular}

Values are means. The Student t-test was used to compare the absence or presence of IVP. cause failed-back surgery syndrome. ${ }^{11}$ In addition, a lordotic alignment of the lumbar fusion influences the biomechanical stresses on the adjacent segments and thus affects the rate of adjacent-level degeneration..$^{20,24}$ The presence of IVP usually indicates a more advanced stage of degeneration and is considered a sign of instability. ${ }^{18,19,27}$ Nevertheless, the increase in spinal mobility when IVP is present might provide greater freedom for spine reconstruction. Based on our study, there were significant increases in disc height and SL after LLIF when IVP was found in preoperative images (Table 3 ). There was a trend toward increased disc height and SL in patients who underwent ALL release and placement of a hyperlordotic cage, but the increase was not statistically significant, likely because of the small number of patients.

\section{Lateral Lumbar Interbody Fusion}

Since its introduction in 2006, LLIF has been popularized and used for the treatment of degenerative disc disease. ${ }^{21}$ The advantages of LLIF are indirect decompression and enhancement of fusion with the placement of a widefootprint cage, achieved through an MIS approach (Fig. 1). The indications of this technique were expanded later to include spinal deformity in patients with either coronal or sagittal imbalance. Placement of a large lordotic cage provides benefits for anterior column support and spine realignment. Our study found that a single-level LLIF provided, on average, a $2.9-\mathrm{mm}$ increase in $\mathrm{PDH}, 5.7-\mathrm{mm}$ increase in $\mathrm{ADH}$, and $4.4^{\circ}$ increase in SL.

In patients with severe sagittal imbalance, posterior shortening or anterior lengthening procedures might be needed to restore alignment. MIS lateral-approach ALL release has become an appealing option for restoring coronal and sagittal balance in spinal deformity through releasing the anterior column and placing a large hyperlordotic interbody cage. Our early reports showed increases in SL between $10^{\circ}$ and $17^{\circ}$ after ALL release and placement of the $30^{\circ}$ cage..$^{7,8,15}$ The study presented here found that a single-level ALL release provided a mean 3.5- $\mathrm{mm}$ increase in $\mathrm{PDH}, 11.3-\mathrm{mm}$ increase in $\mathrm{ADH}$, and $13.5^{\circ}$ increase in SL. It should be noted that a hyperlordotic cage and more anterior placement of the cage did not increase PDHs significantly. One must exercise caution with placement of a lordotic cage anteriorly, because subsequent compression of the posterior elements can cause a fulcrum effect at the 
posterior vertebral body and subsequent neuroforaminal stenosis, which can either exacerbate or create foraminal stenosis and subsequent radiculopathy. The resultant increased SL did not match the angle of the hyperlordotic cage in this series of patients, which is to be expected, because we did not perform any posterior column osteotomies. A posterior column osteotomy is required to achieve the desired SL, as demonstrated in computer modeling and clinical case series. ${ }^{7,26}$

\section{Addition of Posterior Instrumentation}

LLIF can be performed as a stand-alone procedure or supplemented with instrumentations such as lateral plating or posterior open or percutaneous pedicle screws/ rods. Because the ALL, posterior longitudinal ligament, and posterior column are not violated, spinal stability is largely maintained with a simple LLIF procedure. However, supplementary instrumentation might be required in patients with osteoporosis, listhesis greater than $3 \mathrm{~mm}$ as a result of pars defects or degeneration, or coronal or sagittal instability and in those in whom 3 or more levels are being treated. ${ }^{1,17}$ In the current study, we chose the addition of percutaneous pedicle screws/rods for patients with osteoporosis, instability, or significant deformity. With the addition of contoured rods, posterior instrumentation can maintain an increase in disc height. Biomechanical data have revealed that stability of the spinal segment with pedicle screw fixation is improved over that with the standalone procedure. ${ }^{4}$

\section{Subsidence}

Cage settling into adjacent vertebral bodies after interbody fusion is not an uncommon occurrence. Depending on the imaging modalities and criteria used to define subsidence, the rate of subsidence after MIS LLIF has been reported to be in the range of $8 \%-14.3 \% .^{12,14,16}$ Subsidence can lead to a loss of indirect decompression and alignment. Many factors contribute to intervertebral cage subsidence, including bone quality, cage morphology, use of biologics, application of supplemental fixation, and iatrogenic endplate violation. Despite the frequency of radiographic subsidence, clinically significant subsidence has been reported for only $2 \%-3 \%$ of patients. ${ }^{12,14}$ The results of our study show that the presence of IVP did not increase the risk of subsidence. The addition of percutaneous pedicle screws and rods reduced the incidence of cage subsidence regardless of the presence or absence of IVP.

\section{Limitations}

We acknowledge that our study was limited by its retrospective nature and relatively short follow-up duration. In addition, CT scans, which have a higher sensitivity for detecting IVP, were not obtained for every patient. Selection of cages of different sizes certainly can affect postoperative PDH, ADH, and SL. After discectomy or ALL release, trials were placed in the disc space for a snug fit, and appropriate cages were selected based on the sizes of the trials. Our practice, however, is to place the largest cage that can be inserted safely. Placement of a cage either anteriorly or posteriorly can affect the imaging outcome, although we followed the published safe zones for placement of these cages. ${ }^{25}$ In this study, $62 \%$ of the patients underwent surgery at more than 1 level. The biomechanics and configuration of the index levels affected by LLIF of the adjacent segments were not taken into consideration. Furthermore, the anatomy of the posterior column (such as facet joints and spinous processes) that could influence disc height and SL restoration was not studied. Finally, because the goals of the study were to evaluate the restoration disc height and SL, patients with more than 6 months of follow-up were included, which resulted in a cohort with wide variations in follow-up time (6-42 months).

\section{Conclusions}

IVP is a common finding in the degenerative spine. The presence of IVP can contribute positively to spinal realignment after LLIF, because its existence potentially provides an improved capacity to create SL and restore disc height. The addition of posterior instrumentation lowers the stress on the interbody cage and reduces the incidence of cage subsidence.

\section{References}

1. Ahmadian A, Bach K, Bolinger B, Malham GM, Okonkwo DO, Kanter AS, et al: Stand-alone minimally invasive lateral lumbar interbody fusion: multicenter clinical outcomes. J Clin Neurosci 22:740-746, 2015

2. Beckman JM, Murray G, Bach K, Deukmedjian A, Uribe JS: Percutaneous minimally invasive (MIS) guide wire-less selftapping pedicle screw placement in the thoracic and lumbar spine: safety and initial clinical experience: technical note. Oper Neurosurg (Hagerstown) 11:530-536, 2015

3. Bielecki DK, Sartoris D, Resnick D, Van Lom K, Fierer J, Haghighi P: Intraosseous and intradiscal gas in association with spinal infection: report of three cases. AJR Am J Roentgenol 147:83-86, 1986

4. Cappuccino A, Cornwall GB, Turner AWL, Fogel GR, Duong $\mathrm{HT}$, Kim KD, et al: Biomechanical analysis and review of lateral lumbar fusion constructs. Spine (Phila Pa 1976) 35 (26 Suppl):S361-S367, 2010

5. Caudron A, Grados F, Boubrit Y, Coullet JM, Merrien D, Domart Y: Discitis due to Clostridium perfringens. Joint Bone Spine 75:232-234, 2008

6. D’Anastasi M, Birkenmaier C, Schmidt GP, Wegener B, Reiser MF, Baur-Melnyk A: Correlation between vacuum phenomenon on CT and fluid on MRI in degenerative disks. AJR Am J Roentgenol 197:1182-1189, 2011

7. Deukmedjian AR, Dakwar E, Ahmadian A, Smith DA, Uribe JS: Early outcomes of minimally invasive anterior longitudinal ligament release for correction of sagittal imbalance in patients with adult spinal deformity. ScientificWorldJournal 2012:789698, 2012

8. Deukmedjian AR, Le TV, Baaj AA, Dakwar E, Smith DA, Uribe JS: Anterior longitudinal ligament release using the minimally invasive lateral retroperitoneal transpsoas approach: a cadaveric feasibility study and report of 4 clinical cases. J Neurosurg Spine 17:530-539, 2012

9. Ford LT, Gilula LA, Murphy WA, Gado M: Analysis of gas in vacuum lumbar disc. AJR Am J Roentgenol 128:10561057,1977

10. Kumar MN, Baklanov A, Chopin D: Correlation between sagittal plane changes and adjacent segment degeneration following lumbar spine fusion. Eur Spine J 10:314-319, 2001

11. Labelle H, Roussouly P, Berthonnaud E, Dimnet J, O'Brien M: The importance of spino-pelvic balance in L5-S1 devel- 
opmental spondylolisthesis: a review of pertinent radiologic measurements. Spine (Phila Pa 1976) 30 (6 Suppl):S27S34, 2005

12. Le TV, Baaj AA, Dakwar E, Burkett CJ, Murray G, Smith DA, et al: Subsidence of polyetheretherketone intervertebral cages in minimally invasive lateral retroperitoneal transpsoas lumbar interbody fusion. Spine (Phila Pa 1976) 37:12681273,2012

13. Li FC, Zhang N, Chen WS, Chen QX: Endplate degeneration may be the origination of the vacuum phenomenon in intervertebral discs. Med Hypotheses 75:169-171, 2010

14. Malham GM, Ellis NJ, Parker RM, Seex KA: Clinical outcome and fusion rates after the first 30 extreme lateral interbody fusions. ScientificWorldJournal 2012:246989, 2012

15. Manwaring JC, Bach K, Ahmadian AA, Deukmedjian AR, Smith DA, Uribe JS: Management of sagittal balance in adult spinal deformity with minimally invasive anterolateral lumbar interbody fusion: a preliminary radiographic study. J Neurosurg Spine 20:515-522, 2014

16. Marchi L, Abdala N, Oliveira L, Amaral R, Coutinho E, Pimenta L: Radiographic and clinical evaluation of cage subsidence after stand-alone lateral interbody fusion. J Neurosurg Spine 19:110-118, 2013

17. Marchi L, Abdala N, Oliveira L, Amaral R, Coutinho E, Pimenta L: Stand-alone lateral interbody fusion for the treatment of low-grade degenerative spondylolisthesis. ScientificWorldJournal 2012:456346, 2012

18. Morishita K, Kasai Y, Uchida A: Clinical symptoms of patients with intervertebral vacuum phenomenon. Neurologist 14:37-39, 2008

19. Murata Y, Kanaya K, Wada H, Wada K, Shiba M, Hatta S, et al: L5 radiculopathy due to foraminal stenosis accompanied with vacuum phenomena of the L5/S disc on radiography images in extension position. Spine (Phila Pa 1976) 40:18311835,2015

20. Oda I, Cunningham BW, Buckley RA, Goebel MJ, Haggerty CJ, Orbegoso CM, et al: Does spinal kyphotic deformity influence the biomechanical characteristics of the adjacent motion segments? An in vivo animal model. Spine (Phila Pa 1976) 24:2139-2146, 1999

21. Ozgur BM, Aryan HE, Pimenta L, Taylor WR: Extreme lateral interbody fusion (XLIF): a novel surgical technique for anterior lumbar interbody fusion. Spine J 6:435-443, 2006

22. Resnick D, Niwayama G, Guerra J Jr, Vint V, Usselman J: Spinal vacuum phenomena: anatomical study and review. Radiology 139:341-348, 1981

23. Schwab FJ, Patel A, Shaffrey CI, Smith JS, Farcy JP, Boachie-Adjei O, et al: Sagittal realignment failures fol- lowing pedicle subtraction osteotomy surgery: are we doing enough? Clinical article. J Neurosurg Spine 16:539-546, 2012

24. Umehara S, Zindrick MR, Patwardhan AG, Havey RM, Vrbos LA, Knight GW, et al: The biomechanical effect of postoperative hypolordosis in instrumented lumbar fusion on instrumented and adjacent spinal segments. Spine (Phila Pa 1976) 25:1617-1624, 2000

25. Uribe JS, Arredondo N, Dakwar E, Vale FL: Defining the safe working zones using the minimally invasive lateral retroperitoneal transpsoas approach: an anatomical study. J Neurosurg Spine 13:260-266, 2010

26. Uribe JS, Harris JE, Beckman JM, Turner AW, Mundis GM, Akbarnia BA: Finite element analysis of lordosis restoration with anterior longitudinal ligament release and lateral hyperlordotic cage placement. Eur Spine J 24 (Suppl 3):420-426, 2015

27. Wang HJ, Chen BB, Yu CW, Hsu CY, Shih TTF: Alteration of disc vacuum contents during prolonged supine positioning: evaluation with MR image. Spine (Phila Pa 1976) 32:26102615, 2007

28. Yen CP, Uribe JS: Procedural checklist for retroperitoneal transpsoas minimally invasive lateral interbody fusion. Spine (Phila Pa 1976) 41 (Suppl 8):S152-S158, 2016

29. Yoshida H, Shinomiya K, Nakai O, Kurosa Y, Yamaura I: Lumbar nerve root compression caused by lumbar intraspinal gas. Report of three cases. Spine (Phila Pa 1976) 22:348351,1997

\section{Disclosures}

Dr. Uribe is a consultant for and has direct stock ownership in NuVasive.

\section{Author Contributions}

Conception and design: Uribe, Yen, Beckman, Bach. Acquisition of data: Yen, Beckman, Bach. Analysis and interpretation of data: Yen, Beckman, Vivas, Bach. Drafting the article: Yen, Vivas. Critically revising the article: Uribe, Yen, Beckman, Vivas. Reviewed submitted version of manuscript: Uribe, Yen, Beckman, Vivas. Approved the final version of the manuscript on behalf of all authors: Uribe. Statistical analysis: Yen. Study supervision: Uribe.

\section{Correspondence}

Juan S. Uribe, Department of Neurological Surgery, University of South Florida, 2 Tampa General Cir., 7th Fl., Tampa, FL 33606. email: juribe@health.usf.edu. 